\title{
CONCENTRAÇÕES DE AMÔNIO NA ÁGUA DA CHUVA E ESTIMATIVA DE EMISSÃO DE AMÔNIA DE REBANHOS DOMÉSTICOS DE PINHEIRO E VIANA, BAIXADA MARANHENSE
}

\author{
Richardson G. Lima* \\ Departamento de Biologia, Universidade Federal do Maranhão, Av. dos Portugueses, s/n, 65040-080 São Luís - MA, Brasil \\ Paulo R. S. Cavalcante e Odilon T. Melo \\ Departamento de Oceanografia e Limnologia, Universidade Federal do Maranhão, Av. dos Portugueses, s/n, 65040-080 São Luís \\ - MA, Brasil \\ William Z. de Mello \\ Departamento de Geoquímica, Instituto de Química, Universidade Federal Fluminense, Outeiro de São João Batista, s/n, \\ 24020-141 Niterói - RJ, Brasil
}

Recebido em 11/7/08; aceito em 11/5/09; publicado na web em 6/10/09

\begin{abstract}
RAINWATER AMMONIUM CONCENTRATIONS AND ESTIMATE OF AMMONIA EMISSIONS FROM DOMESTIC ANIMALS IN PINHEIRO AND VIANA, BAIXADA MARANHENSE. Rainwater samples (bulk deposition samples) were collected in Pinheiro and Viana. Rainwater pHs were higher than the range usually expected for unpolluted rain (5.0-5.6). The highest values were found in the beginning of the rainy season. High concentrations of ammonium found in the rainwater samples could probably explain the high pHs. Grazing animals and other human activities, combined with soil characteristics and climatic conditions can be the potential factors controlling the rainwater concentrations of ammonium in Baixada Maranhense.
\end{abstract}

Keywords: rainwater; ammonium; Baixada Maranhense.

\section{INTRODUÇÃo}

A amônia $\left(\mathrm{NH}_{3}\right)$ é um gás bastante solúvel em água. Entre suas várias aplicações, se destaca o uso na fabricação de fertilizantes, como agente neutralizador na indústria de petróleo e como gás de refrigeração em sistemas industriais. ${ }^{1}$ Algumas fontes naturais de amônia incluem a superfície marinha e as emissões do solo, mas algumas atividades antrópicas (como queima de combustíveis fósseis, uso de fertilizantes nitrogenados e atividades pecuárias) têm provocado desequilíbrios nos ciclos naturais. ${ }^{1-6}$

$\mathrm{Na}$ atmosfera, a amônia possui um tempo de residência que varia de uma a duas semanas, podendo ser retirada desta por processos físicos de deposições seca e úmida ou ainda, em menor proporção, por processos fotoquímicos. ${ }^{1-4}$ Uma parte substancial dos ácidos gerados pela oxidação do dióxido de enxofre $\left(\mathrm{SO}_{2}\right)$ e dos óxidos de nitrogênio $\left(\mathrm{NO}_{\mathrm{x}}\right)$ é neutralizada pela amônia, gerando sais de amônio $\left(\mathrm{NH}_{4}^{+}\right)$ na forma particulada. ${ }^{1,7,8}$ Essas partículas compõem a fração fina dos aerossóis atmosféricos (diâmetro aerodinâmico inferior a 2,5 $\mu \mathrm{m}$ ) e provocam efeitos adversos à saúde humana. ${ }^{1}$ Portanto, a amônia pode ser considerada um contaminante atmosférico, desde que seja emitida em quantidades suficientes para produzir concentrações locais mais elevadas que a concentração ambiental. ${ }^{3}$

O monitoramento atmosférico de espécies químicas de importância ambiental é uma prática que tem aumentado consideravelmente nos últimos anos, devido à crescente necessidade de se controlar a poluição em grandes centros urbanos, bem como evitar impactos negativos aos sistemas naturais. Assim, o conhecimento da composição química da água da chuva, juntamente com a análise das possíveis fontes de contribuição (naturais e antrópicas), é essencial para o entendimento e controle das atividades humanas sobre o meio ambiente. ${ }^{3}$

Este trabalho teve por objetivo determinar as concentrações de amônio na água da chuva em dois municípios da Baixada Maranhense,

*e-mail: richlima@yahoo.com.br bem como estimar a potencial contribuição de rebanhos domésticos como fontes locais de amônia para a atmosfera.

\section{PARTE EXPERIMENTAL}

\section{Área de estudo}

Este estudo foi realizado nas cidades de Pinheiro e Viana, capitais de dois dos vinte e um municípios que constituem a Baixada Maranhense. Localizada a noroeste do Estado do Maranhão, a Baixada Maranhense possui o maior conjunto de bacias lacustres do nordeste, com predominância de terras planas, baixas e inundáveis, e vegetação de manguezais, campos aluviais e flúvio-marinhos. ${ }^{9,10}$ Possui uma área de $17.579 \mathrm{~km}^{2}$ e uma população de aproximadamente $518 \mathrm{mil}$ habitantes. As estações climáticas são bem definidas, a chuvosa, que abrange o período de janeiro a junho, e a seca, de julho a dezembro. As precipitações encontram-se em torno de $2.000 \mathrm{~mm}$ anuais, com ocorrência de quase $90 \%$ do total de chuva nos primeiros seis meses do ano.

Os campos naturais da Baixada Maranhense servem como áreas de pastoreio para o gado bovino e bubalino durante os meses de julho a dezembro, período em que a incidência de chuvas no estado é menor. ${ }^{10}$ Porém, de janeiro a junho os campos tornam-se totalmente inundados, favorecendo uma elevada produtividade e biodiversidade, ${ }^{11}$ sobretudo de peixes, principal base alimentar e econômica da região. ${ }^{10,11}$

O município de Pinheiro ( $2^{\circ} 30^{\prime}-2^{\circ} 45^{\prime} \mathrm{S} ; 45^{\circ} 00^{\prime}-45^{\circ} 15^{\prime} \mathrm{W}$ ) situase na bacia hidrográfica do rio Pericumã e possui uma área de 1.466 $\mathrm{km}^{2}$, com uma população de cerca de 74.100 habitantes. ${ }^{12}$ A região apresenta um grande mosaico de vegetação, o qual se alterna entre o cerrado aberto nas chapadas e os campos inundáveis nas planícies. Também estão presentes as matas de igapó nas margens de rios e lagos, bem como capoeiras e babaçuais nas áreas de terra firme. ${ }^{13} \mathrm{~A}$ precipitação total da região situa-se acima de $2.000 \mathrm{~mm}$ anuais, ${ }^{11,14}$ com temperaturas variando entre 25 e $30{ }^{\circ} \mathrm{C} .1^{14}$

O município de Viana ( $\left.3^{\circ} 00^{\prime}-3^{\circ} 15^{\prime} \mathrm{S} ; 4^{\circ} 00^{\prime}-45^{\circ} 15^{\prime} \mathrm{W}\right)$ possui uma área de aproximadamente $1.162 \mathrm{~km}^{2}$ e população de cerca de 47.500 
habitantes, ${ }^{12}$ sendo banhado por trechos dos rios Mearim, Pindaré e Maracu, este último genuinamente municipal. Existem também vários lagos, destacando-se o lago de Viana, localizado ao sul do município e em pleno perímetro urbano. ${ }^{15} \mathrm{O}$ clima da região parece oscilar entre o Equatorial e o Subtropical, com temperaturas médias anuais em torno de $27^{\circ} \mathrm{C}$ e índices pluviométricos acima de $2.000 \mathrm{~mm} \cdot{ }^{14}$

\section{Coleta de amostras}

Amostras de chuva (deposição total) foram coletadas em 2 pontos da Baixada Maranhense (cidades de Pinheiro e Viana), entre 01/01/2006 e 30/06/2006, por meio de funis de polipropileno com $24 \mathrm{~cm}$ de diâmetro, instalados a $2 \mathrm{~m}$ de altura do solo e conectados a garrafões de $20 \mathrm{~L}$ por intermédio de mangueiras plásticas. Antes do primeiro uso e de cada reutilização, os coletores foram lavados com solução de água e detergente neutro (Extran, Merk) e enxaguados pelo menos sete vezes com água destilada.

As coletas foram efetuadas semanalmente. Alíquotas de água de chuva (pelo menos $350 \mathrm{~mL}$ ) foram retiradas de cada coletor, armazenadas e congeladas para posteriores análises físico-químicas em laboratório. No campo foram efetuadas as medidas de $\mathrm{pH}$ e condutividade através de um aparelho Hanna, modelo 8314, em alíquotas não filtradas de cada amostra. Para calibração foram utilizadas soluções tampão (4,0 e 6,89) para o $\mathrm{pH}$ e de $\mathrm{KCl} 0,01 \mathrm{M}\left(1413 \mu \mathrm{S} \mathrm{cm}^{-1}\right)$ para a condutividade. De cada amostra foram reservados $150 \mathrm{~mL}$ para análises de $\mathrm{NO}_{3}, \mathrm{SO}_{4}{ }_{4}^{2-}$ e $\mathrm{Cl}^{-}$no laboratório na Universidade Federal Fluminense e o restante foi utilizado para análises dos demais íons $\left(\mathrm{Na}^{+}, \mathrm{K}^{+}, \mathrm{Mg}^{2+}, \mathrm{Ca}^{2+} \mathrm{e} \mathrm{NH}_{4}^{+}\right)$no Laboratório de Oceanografia da Universidade Federal do Maranhão. Neste trabalho serão considerados apenas os resultados de $\mathrm{NH}_{4}^{+}$.

\section{Análises químicas}

No laboratório, as amostras foram deixadas à temperatura ambiente até total descongelamento e, em seguida, filtradas em membranas de acetato de celulose (Millipore) de $0,45 \mu \mathrm{m}$ de diâmetro. O íon amônio $\left(\mathrm{NH}_{4}^{+}\right)$foi determinado pelo método espectrofotométrico do azul de indofenol, um complexo que se forma a partir da reação da amônia com o ácido isocianúrico e fenol. A absorbância foi medida em um espectrofotômetro Hitachi, modelo U-1100. O limite de detecção das determinações de amônio foi $0,2 \mu \mathrm{mol} \mathrm{L}^{-1}\left(3,6 \mu \mathrm{g} \mathrm{L}^{-1}\right)$ com uma precisão na faixa de $\pm 5 \%$.

\section{RESULTADOS E DISCUSSÃO}

Foram coletadas no total 30 amostras de chuva (precipitação total) com volumes superiores a $350 \mathrm{~mL}$, sendo $12 \mathrm{em}$ Pinheiro e 18 em Viana. Do total, a maior parte (80\%) apresentou valores de $\mathrm{pH}$ superiores a 5,6 (valor que resulta exclusivamente da dissolução do $\mathrm{CO}_{2}$ atmosférico em água pura), principalmente nos meses de janeiro e fevereiro, que marcam o início das chuvas no estado (Tabela 1). Ainda do total, $43 \%$ apresentaram valores de $\mathrm{pH}$ superiores a 6,0. Atribui-se os elevados valores de $\mathrm{pH}$ às altas concentrações de amônio encontradas nas amostras de chuva nesse período, cuja média aritmética foi $25 \mu \mathrm{mol} \mathrm{L}^{-1}$ (mediana $=17 \mu \mathrm{mol} \mathrm{L}^{-1} ; \mathrm{n}=30$ ). $\mathrm{O}$ pH médio, calculado a partir da concentração média de $\mathrm{H}^{+}$, foi de 5,6. Individualmente, a concentração média de $\mathrm{NH}_{4}{ }^{+}$foi superior em Pinheiro (média $=30 \mu \mathrm{mol} \mathrm{L}^{-1}$; mediana $=21 \mu \mathrm{mol} \mathrm{L}^{-1} ; \mathrm{n}=12$ ) em relação a Viana (média $=22 \mu \mathrm{mol} \mathrm{L}^{-1}$; mediana $=17 \mu \mathrm{mol} \mathrm{L}^{-1}$; $\mathrm{n}=18$ ). Os valores médios do $\mathrm{pH}$ em Pinheiro e Viana foram 5,6 $($ mediana $=6,1)$ e $5,8($ mediana $=6,0)$, respectivamente.

A concentração média de $\mathrm{NH}_{4}^{+}$em Pinheiro e Viana é uma ordem de grandeza superior à média anual $\left(2 \mu \mathrm{mol} \mathrm{L}^{-1}\right)$ encontrada por Pérez ${ }^{16}$ na Lagoa do Caçó (município de Primeira Cruz, Maranhão), situada a aproximadamente $40 \mathrm{~km}$ a sudoeste dos Lençóis Maranhenses e 200 km a leste-nordeste de Pinheiro. As concentrações médias mensais de amônio na chuva dos municípios da Baixada Maranhense são semelhantes ou superam as médias aritméticas anuais verificadas na Região Metropolitana do Rio de Janeiro ${ }^{17}\left(21 \mu \mathrm{mol} \mathrm{L}^{-1}\right)$ e na Ilha Grande ${ }^{7}(13$ $\mu \mathrm{mol} \mathrm{L}{ }^{-1}$ ), situada na costa sul do Estado do Rio de Janeiro. Na região central de São Paulo, Leal et al. ${ }^{18}$ reportaram média aritmética anual de amônio de $49 \mu \mathrm{mol} \mathrm{L}{ }^{-1}$ e indicaram como potenciais fontes de amônia a decomposição da matéria orgânica de esgotos e lixo urbano, a eliminação metabólica de humanos e animais, a queima de biomassa e veículos equipados com catalisadores de três vias. ${ }^{18}$

A Figura 1 mostra as variações das concentrações médias mensais de amônio e médias de $\mathrm{pH}$ ao longo do período das chuvas. Nos dois locais, mas especialmente em Pinheiro, esses parâmetros mostram tendências temporais semelhantes, sugerindo que a dissolução da amônia possa ser o principal fator de controle do $\mathrm{pH}$ da água da chuva nas áreas estudadas. Sendo assim, quanto maior a concentração de amônio maior é o $\mathrm{pH}$, devido à protonação da amônia $\left[\mathrm{NH}_{3}(\mathrm{~g})+\mathrm{H}^{+}\right.$ (aq) $\rightarrow \mathrm{NH}_{4}^{+}$(aq)]. Embora as médias mensais das concentrações de amônio e $\mathrm{pH}$ apresentem tendências semelhantes e que podem justificar esse controle, é importante salientar que os valores dos coeficientes de correlação linear ( $r$ ) entre amônio e pH não são estatisticamente significativos quando os dados são tratados individualmente para cada local de estudo. Os valores de $r$ calculados para Pinheiro e Viana são, respectivamente, $0,524(\mathrm{n}=12)$ e $0,011(\mathrm{n}=18)$, inferiores aos valores críticos para $r$, que para $\mathrm{P}<0,05$ são, respectivamente, 0,576 e $0,468 .{ }^{19}$

Ocorrências de fontes de amônia locais e regionais, combinadas a fatores climáticos, podem explicar as concentrações elevadas de amônio nas amostras de chuva. As principais fontes potenciais emissoras de amônia relacionadas às atividades antrópicas locais são a pecuária e as queimadas (queima de biomassa vegetal). Considerandose a ausência ou menor frequência de queimadas durante o período das chuvas (janeiro-junho), a contribuição da atividade pecuária na Baixada Maranhense deve ser considerada como a principal nesse período. Além disso, a Zona de Convergência Intertropical (ZCIT) provoca diminuição da velocidade do vento na região entre os meses de janeiro e abril ${ }^{20}$ (maior parte do período das chuvas), o que pode acarretar numa menor dispersão da amônia, favorecendo sua deposição nas proximidades de suas áreas-fonte.

Tabela 1. Médias aritméticas mensais das concentrações de amônio $\left(e m \mu m o l L^{-1}\right)$ e $\mathrm{pH}$ em amostras de água de chuva de Pinheiro $(\mathrm{n}=12)$ e Viana (n = 18), Baixada Maranhense, no período de janeiro a junho de 2006

\begin{tabular}{|c|c|c|c|c|c|c|c|c|c|c|c|c|}
\hline & \multicolumn{2}{|c|}{ Janeiro } & \multicolumn{2}{|c|}{ Fevereiro } & \multicolumn{2}{|c|}{ Março } & \multicolumn{2}{|c|}{ Abril } & \multicolumn{2}{|c|}{ Maio } & \multicolumn{2}{|c|}{ Junho } \\
\hline & $\mathrm{NH}_{4}^{+}$ & $\mathrm{pH}$ & $\mathrm{NH}_{4}^{+}$ & $\mathrm{pH}$ & $\mathrm{NH}_{4}^{+}$ & $\mathrm{pH}$ & $\mathrm{NH}_{4}^{+}$ & $\mathrm{pH}$ & $\mathrm{NH}_{4}^{+}$ & $\mathrm{pH}$ & $\mathrm{NH}_{4}^{+}$ & $\mathrm{pH}$ \\
\hline Pinheiro & $\begin{array}{l}44,4 \\
(4)^{*}\end{array}$ & 6,5 & ND & ND & $\begin{array}{c}39,6 \\
(2)\end{array}$ & 6,2 & $\begin{array}{c}12,1 \\
(4)\end{array}$ & 5,2 & $\begin{array}{c}27,2 \\
\text { (2) }\end{array}$ & 5,9 & $\mathrm{ND}$ & ND \\
\hline Viana & $\begin{array}{c}38,4 \\
\text { (3) }\end{array}$ & 6,3 & ND & ND & $\begin{array}{c}26,0 \\
(5)\end{array}$ & 5,7 & $\begin{array}{c}15,6 \\
(4)\end{array}$ & 5,9 & $\begin{array}{c}14,2 \\
(4)\end{array}$ & 5,7 & $\begin{array}{c}18,3 \\
\text { (2) }\end{array}$ & 5,8 \\
\hline
\end{tabular}

$\mathrm{ND}$ = não determinado devido à ausência de chuvas no período; *Valores entre parênteses representam o número mensal de amostras de água de chuva. 


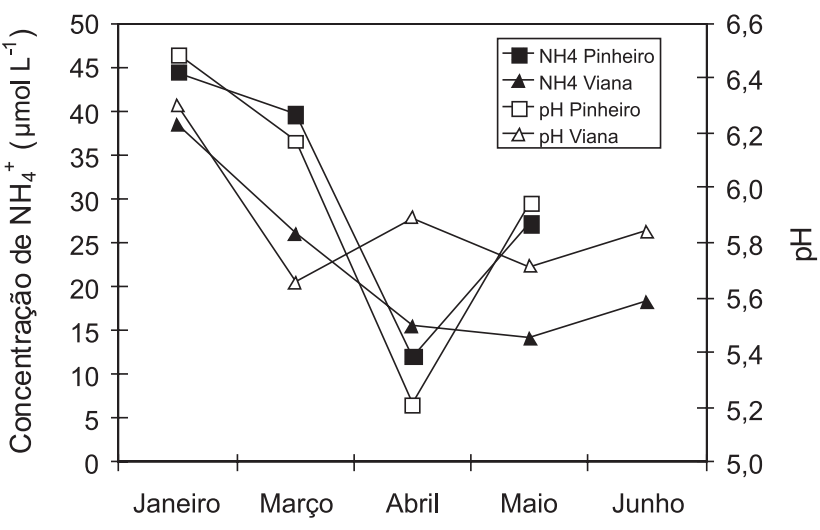

Figura 1. Médias mensais das concentrações de amônio e pH nas águas de chuva de Pinheiro e Viana (Baixada Maranhense) de janeiro a junho de 2006

A atividade pecuária na Baixada Maranhense destaca-se pelo seu crescimento nos últimos anos. Como as fezes e a urina dos animais são fontes de amônia, que se forma a partir da hidrólise da uréia $\left[\left(\mathrm{NH}_{2}\right)_{2} \mathrm{CO}+\mathrm{H}_{2} \mathrm{O} \rightarrow 2 \mathrm{NH}_{3}+\mathrm{CO}_{2}\right]$, buscou-se, através dos dados de efetivo de animais fornecidos pelo Instituto Brasileiro de Geografia e Estatística (IBGE) ${ }^{12}$ e dos fatores de emissão utilizados por Yamaji et al..$^{21}$ para estimativa das emissões de amônia de animais domésticos em alguns países da Ásia, estimar as emissões de amônia para a atmosfera para a área de estudo. A taxa de emissão de amônia por categoria de animal (asinino, aves, bovino, bubalino, caprino, equino, muar, ovino e suíno) foi calculada através da Equação 1:

$\mathrm{TE}_{i}=\mathrm{FE}_{i} \times \mathrm{PA}_{i}$

onde $\mathrm{TE}_{i}$ é a taxa de emissão de amônia (em $\mathrm{kg} \mathrm{NH}_{3}-\mathrm{N}_{\text {ano }}{ }^{-1}$ ) por categoria de animal $i, \mathrm{FE}_{i}$ é o fator de emissão (em kg NH$-\mathrm{N}$ indivíduo $^{-1} \mathrm{ano}^{-1}$ ) e $\mathrm{PA}_{i}$ é população de animais (número de indivíduos).

Os contingentes populacionais de animais domésticos dos municípios de Viana e Pinheiro, os fatores de emissão por categoria de efetivo animal e as taxas de emissão de amônia calculadas encontram-se compilados na Tabela 2. A taxa de emissão de amônia (em

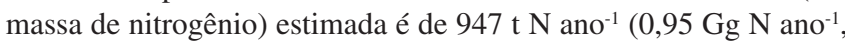
$1 \mathrm{G}=10^{9}$ ), dos quais $23 \%$ são atribuídos a Pinheiro e $77 \%$ a Viana. Considerando-se a área total dos dois municípios $\left(2.628 \mathrm{~km}^{2}\right)$, esta taxa de emissão representa um fluxo médio de emissão de amônia oriunda de animais domésticos da ordem $3,6 \mathrm{~kg} \mathrm{~N} \mathrm{ha}^{-1} \mathrm{ano}^{-1}$ (1 ha = $\left.10^{4} \mathrm{~m}^{2}=0,01 \mathrm{~km}^{2}\right)$.

Com base no produto da concentração média de amônio medida nas amostras de água de chuva em Pinheiro e Viana $\left(25 \mu \mathrm{mol} \mathrm{L}^{-1}\right)$ com a precipitação média anual na região, que é de aproximadamente 2.000 $\mathrm{mm}$, estima-se um aporte atmosférico de amônio de quase $7,0 \mathrm{~kg} \mathrm{~N} \mathrm{ha}^{-1}$ $\mathrm{ano}^{-1}$, valor quase duas vezes superior à emissão de amônia atribuída aos rebanhos desses municípios $\left(3,6 \mathrm{~kg} \mathrm{~N} \mathrm{ha}^{-1} \mathrm{ano}^{-1}\right)$. Alguns fatores podem, isoladamente ou combinados, justificar a incompatibilidade entre os valores estimados dos fluxos de emissão de amônia e de deposição de amônio. No caso dos fluxos de emissão de amônia, não se estimou a contribuição de outras fontes (naturais e antrópicas) como, por exemplo, solos, sistemas aquáticos costeiros e marinhos, vegetação e esgotos domésticos. Sistemas aquáticos costeiros e marinhos que atuam como corpos receptores de esgotos domésticos não tratados tendem a emitir amônia para a atmosfera. ${ }^{7} \mathrm{O}$ transporte a longa distância de poluentes atmosféricos (inclusive amônia) procedentes da Região Metropolitana de São Luís (RMSL) e a possibilidade de deposição na Baixada Maranhense deve ser investigada no futuro. Na RMSL (com 1,21 milhões de habitantes), situada a cerca de $90 \mathrm{~km}$ a leste de Pinheiro e $110 \mathrm{~km}$ a nordeste de Viana, os ventos predominantes são os de nordeste, de janeiro a abril, e de leste, em maio e junho, ${ }^{22}$ o que favorece o transporte de poluentes atmosféricos, procedentes do setor urbano e industrial da RMSL, em direção à Baixada Maranhense.

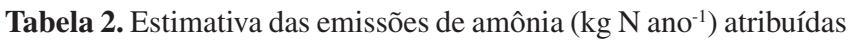
aos rebanhos domésticos de mamíferos e aves dos municípios de Pinheiro e Viana, na Baixada Maranhense

\begin{tabular}{lccccc}
\hline \multirow{2}{*}{$\begin{array}{l}\text { Tipo } \\
\text { rebanho }\end{array}$} & \multicolumn{2}{c}{$\begin{array}{c}\text { Efetivo do rebanho* } \\
\text { Pinheiro }\end{array}$} & $\begin{array}{c}\text { Fatores de } \\
\text { emissão }\end{array}$ & \multicolumn{2}{c}{ Taxas de emissão } \\
Pinheiro & Viana \\
\hline Asinino & 417 & 1.027 & 7,0 & 2.919 & 7.189 \\
Aves & 91.008 & 121.631 & 0,12 & 10.921 & 14.596 \\
Bovino & 23.389 & 20.162 & 5,6 & 130.978 & 112.907 \\
Bubalino & 3.285 & 21.602 & 3,4 & 11.169 & 530.069 \\
Caprino & 3.825 & 2.634 & 1,1 & 4.207 & 2.897 \\
Eqüino & 2.224 & 2.479 & 7,0 & 15.568 & 17.353 \\
Muar & 823 & 1.685 & 7,0 & 5.761 & 11.795 \\
Ovino & 734 & 529 & 1,4 & 1.028 & 741 \\
Suíno & 23.865 & 20.764 & 1,5 & 35.798 & 31.146 \\
Total & 149.570 & 192.513 & - & 218.349 & 728.693 \\
\hline
\end{tabular}

$* \mathrm{IBGE}^{12}$.** Valores, em kg NH${ }_{3}-\mathrm{N}_{\text {indivíduo }}{ }^{-1}$ ano $^{-1}$, adotados por Yamaji et al. $^{21}$ para sistemas de gestão de resíduos de origem animal na Ásia.

Características físicas, químicas e biológicas dos solos e sedimentos desempenham papel importante na dinâmica do nitrogênio, ao qual se inserem os processos de produção e transferência da amônia para a atmosfera. A partir da mineralização da matéria orgânica nos solos e sedimentos ocorre a formação do nitrogênio amoniacal, $\mathrm{NH}_{\mathrm{x}}\left(\mathrm{NH}_{\mathrm{x}}=\right.$ $\left.\mathrm{NH}_{4}^{+}+\mathrm{NH}_{3}\right) . \mathrm{O} \mathrm{pH}$ determina a distribuição entre a forma que permanece no substrato $\left(\mathrm{NH}_{4}^{+}\right)$e aquela sujeita à volatilização para a atmosfera $\left(\mathrm{NH}_{3}\right)$. Por outro lado, sob condições aeróbias, o nitrogênio amoniacal pode ser consumido pela ação microbiológica no processo de nitrificação, sendo convertido a nitrito $\left(\mathrm{NO}_{2}^{-}\right)$e nitrato $\left(\mathrm{NO}_{3}^{-}\right)$. Portanto, o teor de matéria orgânica, o pH e a disponibilidade de oxigênio constituem fatores importantes no controle dos níveis de nitrogênio amoniacal nesses sistemas. Além disso, a textura, a mineralogia da fração argila, a capacidade de troca catiônica, a umidade e a temperatura são outros fatores que podem influenciar na fixação do amônio ou volatilização da amônia nos solos e sedimentos. Solos saturados por água e com elevado $\mathrm{pH}$, como os da Baixada Maranhense, podem contribuir para o acréscimo dos níveis de amônia na atmosfera.

No que tange às influências antrópicas, ausência de sistemas de tratamento de esgoto sanitário, lançamento de esgotos não tratados em corpos d'água, depósitos e queima de lixo urbano, emissões veiculares e queima de biomassa são algumas das potenciais fontes emissoras de amônia na área de estudo. Portanto, são vários os processos naturais e antrópicos que, simultaneamente, podem justificar os elevados níveis de amônio verificados nas águas das chuvas da Baixada Maranhense. Estimativas das emissões de amônia dessas outras potenciais fontes são de maior complexidade e fogem ao escopo do presente trabalho, embora devam ser investigadas no futuro.

\section{CONCLUSÕES}

As amostras de água de chuva coletadas nos municípios de Pinheiro e Viana, no período de janeiro a junho de 2006, apresentaram predominantemente valores de $\mathrm{pH}$ superiores àqueles encontrados em regiões remotas do planeta ou pouco influenciadas pelas atividades humanas $(5,0-5,6)$. Tal fato pode ser explicado pelos altos teores de amônio encontrados 
nas chuvas dessas localidades. Com base nos dados estatísticos recentes relativos às populações dos principais animais criados para produção de alimento e uso para locomoção e transporte de carga, estima-se que os dois municípios contribuam com uma emissão de amônia da ordem de $1.150 \mathrm{t} \mathrm{NH}_{3}$ ano $^{-1}\left(950 \mathrm{t} \mathrm{N}\right.$ ano $\left.^{-1}\right)$. Entretanto, esse montante parece ser insuficiente para explicar o aporte de amônio estimado. Outras fontes naturais e antrópicas podem também contribuir para as concentrações elevadas de amônio encontradas nas chuvas de Pinheiro e Viana, tais como solos, sedimentos, sistemas aquáticos, esgotos não tratados, lixos urbanos, emissões veiculares e queimadas. Além disso, deve-se ressaltar que a origem do amônio na água da chuva se dá através da dissolução da amônia e dissolução de partículas de sais como bissulfato, sulfato e nitrato de amônio. Essas partículas encontram-se predominantemente associadas à fração fina (i.e., partículas de tamanho inferior a 2,5 $\mu \mathrm{m}$ ) e, portanto, podem ser transportadas por longas distâncias. Poluentes atmosféricos emitidos da Região Metropolitana de São Luís tendem a ser transportados em direção à Baixada Maranhense pelos ventos predominantes de nordeste-leste (NE-E).

\section{AGRADECIMENTOS}

À Coordenação de Aperfeiçoamento de Pessoal de Nível Superior - CAPES e à coordenação do Mestrado em Sustentabilidade de Ecossistemas, pelo apoio financeiro e logístico concedido a este projeto, a Valdilson e Nivaldo, pela imprescindível colaboração na coleta e estocagem das amostras, e a H. C. Gomes, R. M. Cutrim e P. A. de Souza, pela ajuda nas análises das mesmas.

\section{REFERÊNCIAS}

1. Felix, E. P.; Cardoso, A. A.; Quim. Nova 2004, 27, 123.

2. Guimarães, G. P.; de Mello, W. Z.; Quim. Nova 2006, 29, 54.

3. Ugucione, C.; Felix, E. P.; Rocha, G. O.; Cardoso, A. A.; Eclet. Quím. 2002, 27, 1 .

4. Finlayson-Pitts, B. J.; Pitts Jr., J. N.; Chemistry of the Upper and Lower Atmosphere, Academic Press: New York, 2000.
5. Smith, R. L.; Smith, T. M.; Ecología, $4^{\text {th }}$ ed., Pearson Educacíon: Madrid, 2001

6. Trivelin, P. C. O.; Oliveira, M. W.; Vitti, A. C.; Gava, G. J. C.; Bendassoli, J. A.; Pesq. agropec. bras. 2002, 37, 193.

7. de Souza, P. A.; de Mello, W. Z.; Maldonado, J.; Evangelista, H.; Quim. Nova 2006, 29, 471.

8. Mariani, R. L.; de Mello, W. Z.; Atmos. Environ. 2007, 41, 2887.

9. Gaspar, S. M. F. S.; Nunes, G. S.; Pinheiro, C. U. B.; Amarante-Jr, O. P. A.; Pesticidas: R. Ecotoxicol. e Meio Ambiente 2005, 15, 43.

10. Costa-Neto, J. P.; Barbieri, R.; Ibáñez, M. S. R.; Cavalcante, P. R. S.; Piorski, N. M.; Bol. Lab. Hidrobiol. 2001, 14, 19.

11. Ibañez, M. S. R.; Cavalcante, P. R. S.; Costa-Neto, J. P.; Barbieri, R.; Pontes, J. P.; Santana, S. C. C.; Serra, C. L. M.; Nakamoto, N.; Mitamura, O.; Aquatic Ecosystem Health and Management 2000, 3, 521.

12. http://www.ibge.gov.br/cidadesat/topwindow.htm?1, acessada em Junho 2008.

13. Pinheiro, C. U. B.; Estudos etnobiológicos: Baixada Maranhense, Universidade Federal do Maranhão, Brasil, 2000.

14. http://www.nemrh.uema.br/meteoro/meteoro.htm, acessada em Outubro 2007.

15. Costa, C. L.; Lima, R. G.; Rodrigues, E. I.; Lopes, I. A.; Santos, M. C. F.; Anais do XI Simpósio Brasileiro de Geografia Física Aplicada, São Paulo, Brasil, 2005.

16. Pérez, M. A. P.; Dissertação de Mestrado, Universidade Federal Fluminense, Brasil, 2003.

17. de Mello, W. Z.; Environ. Pollut. 2001, 114, 235.

18. Leal, T. F. M.; Fontenele, A. P. G.; Pedrotti, J. J.; Fornaro, A.; Quim. Nova 2004, 27, 855.

19. Rohlf, F. J.; Sokal, R. R.; Statistical Tables, W. H. Freeman and Company: New York, 1981.

20. Silva-Dias, M. A. F.; Cohen, J. C. P.; Gandu, A. W.; Acta Amazonica 2005, 35, 215.

21. Yamaji, K.; Ohara, T.; Akimoto, H.; Atmos. Environ. 2004, 38, 7111.

22. Silva, B. B.; Alves, J. J. A.; Cavalcanti, E. P.; Dantas, R. T. R.; Rev. bras. eng. agríc. ambiental 2002, 6, 431 . 